\title{
Quit or Die: Nothing in between?
}

\author{
Karl Fagerström \\ Fagerstrom Consulting AB, Helsingborg, Sweden
}

When asked about their interest in stopping smoking sometime in the future, $54 \%$ of smokers in the European Union state such an interest [1]. However, not all of these smokers actually make a serious attempt to give up and only a few percent succeed at each attempt [2]. Despite all kinds of approaches to control smoking, little is being done to decrease the prevalence of smoking in Europe. Smoking shortens the life of $50 \%$ of long-term smokers. Given this scenario, new ways to address this health problem need to be developed [3]. The need to find new approaches is even more compelling in the case where patients with severe COPD are either unable or unwilling to give up smoking with the traditional 'abrupt-quitting' method. For many physicians it is common to ask the patients to smoke less rather than give up smoking. This advice may be a way not to be too harsh with the patient, or even a solution for those who have failed to quit during many earlier attempts. The soft advice to smoke less almost always fails, mostly because the smoker is dependent on nicotine and therefore usually rapidly returns to the normal smoking rate. Most researchers and clinicians interested in the treatment of tobacco dependence know this. Therefore the prevailing attitude is not to give advice to smoke less or reduce smoking. The new approach suggested by Jiménez et al. [4] in this issue of Respiration is to substitute the 'lost' nicotine from an alternative source, e.g. from a nicotine chewing gum. Earlier studies $[5,6]$ have shown that nicotine replacement (NR) can aid smoking reduction in healthy subjects and also improve risk factors, e.g., cardiovascular disease [7, 8]. In the study of Jiménez et al. [4], 17 smokers with severe COPD who were unable or unwilling to stop smoking were offered to reduce their smoking with the aid of NR. Their tobacco dependence was severe, on average 9 points on the Fagerström Test for Nicotine Dependence (FTND), which ranges from 0 to 10 . In a representative sample of smokers, only about $2 \%$ can be expected to have a dependence $>8$ points on the FTND [9]. Success in giving up smoking is related to the degree of dependence. Usually no more than $5-10 \%$ of smokers so heavily dependent can be expected to give up long term. Having moderate to severe COPD is a negative prognostic factor for giving up smoking, so if anything, a lower percentage could be expected. This means that if Jiménez et al. [4] had insisted on the 17 smokers to give up completely and abruptly, 1 , or 2 at most, might have been able to give up long term. This would mean a reduction of 39-78 cigarettes per day (CPD); the mean baseline smoking was 39 CPD. That outcome should be compared to the 5 patients who reduced cigarette consumption by $85 \%$, i.e. 165 CPD in total. Such a comparison has its weaknesses, since 1 or 2 patients would not have smoked at all, and it is possible that harm reduction is not linearly related to the reduction in the number of cigarettes smoked.

What is particularly intriguing with this study is that we do not just observe a reduction in cigarettes smoked, but a consistent improvement in lung function, i.e. harm reduction. Reduced smoking can result in harm reduc-

\begin{tabular}{ll}
\hline KARGER & (c) 2002 S. Karger AG, Basel \\
Fax +4161306 1234 & 0025-7931/02/0695-0387\$18.50/0 \\
$\begin{array}{l}\text { E-Mail karger@karger.ch } \\
\text { www.karger.com }\end{array}$ & $\begin{array}{l}\text { Accessible online at: } \\
\text { www.karger.com/journals/res }\end{array}$
\end{tabular}

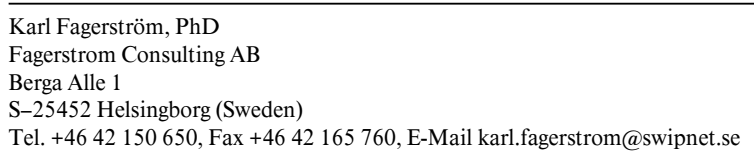


tion, but not necessarily. It is also worth noticing the trend towards declining numbers of CPD over time. Hopefully, 1 or 2 of the 5 reducers can also finally give up smoking altogether after a long reduction period, as seen in another case study [10].

No firm conclusion can be drawn from this non-controlled study. However, an interesting feature of this case study is the link between continued long-term use of NR and improved lung function. This can be a quasi-relationship, in the sense that those who could forego their ciga- rettes more easily may have been more likely to use nicotine gum and enjoy the benefits. Clearly, these results are so interesting that they warrant to be further investigated in controlled studies, e.g. in a randomised study where one group is given only advice and support for abrupt quitting, and another group receives the same support, but also a reduction approach for those who do not want to quit, cannot quit, or relapse - the more so as, to my knowledge, no study of smoking reduction has found a decline in the intention to give up smoking.

\section{References}

1 Fagerström KO, Boyle P, Kunze M, Zatonski W: The anti-smoking climate in EU countries and Poland. Lung Cancer 2000;32:1-5.

2 Hughes JR: Tobacco withdrawal in self-quitters. J Consult Clin Psychol 1992;60:689-697.

3 World Health Organisation, Statement on Treatment for Tobacco Dependence. www. whostate.htm

4 Jiménez-Ruiz C, Solano S, Alonso Viteri S, Barrueco Ferrero R, Torrecilla M, Hernández Mezquita M: Harm reduction - A treatment approach for resistant smokers with tobaccorelated symptoms. Respiration 2002;69:452455 .
5 Rennard S, Daughton D, Fujita J: Short-term smoking reduction is associated with reduction in measures of lower respiratory tract inflammation in heavy smokers. Eur Respiratory $\mathbf{J}$ 1990:3:752-759.

6 Bolliger C, Zellweger P, Danielsson T, van Biljon X, Robidou A, Westin A, Perruchond A, Sawe U: Smoking reduction with oral nicotine inhalers: Double blind, randomised clinical trial of efficacy and safety. BMJ 2000;321:329_ 333.

7 Bolliger CT, Zellweger JP, Danielsson T, Biljon $\mathrm{X}$, Robidou A, Westin A, Perruchoud AP, Säwe U: Influence of long-term smoking reduction on health risk markers and quality of life. Nicotine Tob Res, in press.
8 Eliasson B, Hjalmarson A, Kruse E, Landfeldt $\mathrm{B}$, Westin $\AA$ : Effect of smoking reduction and cessation on cardiovascular risk factors. Nicotine Tob Res 2001;3:249-255.

9 Fagerström KO, Kunze M, Scoberberger R, Breslau N, Hughes J, Hust RD, Puska P, Ramstrom L, Zatanski W: Nicotine dependence versus smoking prevalence: Comparisons among countries and categories of smokers. Tob Control 1996;5:52-56.

10 Fagerström KO: From reduced smoking to quitting: Improvements in COPD symptoms and lung function. A case report. Nicotine Tob Res 2001;3:93-94. 